\title{
Gut Microbiota-Induced 5-HT Synthesis and Obesity
}

\author{
Katsunori Nonogaki* \\ Department of Diabetes Technology, Tohoku University of Graduate School of Biomedical Engineering
}

Received: December 09, 2015; Accepted: December 15, 2015; Published: December 19, 2015

*Corresponding author: Katsunori Nonogaki, Department of Diabetes Technology, Tohoku University of Graduate School of Biomedical Engineering, 6-6-11 Aramakiaza, Aoba, Aoba-ku, Sendai, Miyagi 980-8579, Japan, Tel: +81-22-795-3865; Fax: +81-22-795-3865; E-mail: katsu@trc.med.tohoku.

ac.jp/knonogaki-tky@umin.ac.jp

\section{Editorial}

Although the role of gut microbiota in type 2 diabetes and the therapeutic effects of metformin have recently been reported [1$3]$, the intestinal microbiota composition may be also influenced by obesity. Microbiota depletion by antibiotic treatment promotes browning of white adipose tissue and improves insulin sensitivity in obese animals such as ob/ob mice and diet-induced obesity [4]. Such metabolic improvements are mediated by eosinophil infiltration, enriched type 2 cytokine signaling and M2 macrophage polarization in the subcutaneous white fat depots [4]. Microbiota composition may therefore influence insulin sensitivity.

Serotonin (5-hydroxytryptamine, 5-HT) is mainly synthesized, stored, and released from enterochromaffin cells within mucosal epithelia of the gut [5]. Gut microbes regulate 5-HT levels in the colon and blood. Spore-forming bacteria (Sp) from the mouse and human microbiota promote 5-HT biosynthesis from colonic enterochromaffin cells [5]. Peripheral 5-HT synthesis is specifically regulated via tryptophan hydroxylase 1 (Tph1). Tph1-deficient mice fed a high-fat diet are protected from obesity, insulin resistance and nonalcoholic fatty liver disease while exhibiting greater energy expenditure by brown adipose tissue [6]. Tph1-deficient mice and microbiota depletion may have similar effects on obesity and energy homeostasis. Thus, the regulation of gut microbiota and 5-HT systems may be a novel therapeutic target for obesity and insulin resistance.

\section{References}

1. Qin J, Li Y, Cai Z, Li S, Zhu J, Zhang F, et al. A metagenome-wide association study of gut microbiota in type 2 diabetes. Nature. 2012;490(7418):55-60. doi: 10.1038/nature11450.

2. Karlsson FH, Tremaroli V, Nookaew I, Bergström G, Behre CJ, Fagerberg B, et al. Gut metagenome in European women with normal, impaired and diabetic glucose control. Nature. 2013;498(7452):99103. doi: $10.1038 /$ nature 12198.

3. Forslund K, Hildebrand F, Nielsen T, Falony G, Le Chatelier E, Sunagawa $\mathrm{S}$, et al. Disentangling type 2 diabetes and metformin treatment signatures in the human gut microbiota. Nature. 2015;528(7581):262266. doi:10.1938/nature15766.

4. Suárez-Zamorano N, Fabbiano S, Chevalier C, Stojanović O, Colin DJ, Stevanović A, et al. Microbiota depletion promotes browning of white adipose tissue and reduces obesity. Nat Med. 2015;21(12):1497-501. doi: $10.1038 / \mathrm{nm} .3994$.

5. Yano JM, Yu K, Donaldson GP, Shastri GG, Ann P, Ma L, et al. Indigenous bacteria from the gut microbiota regulate host serotonin biosynthesis. Cell. 2015;161(2):264-276. doi: 10.1016/j.cell.2015.02.047.

6. Crane JD, Palanivel R, Mottillo EP, Bujak AL, Wang H, Ford RJ, et al. Inhibiting peripheral serotonin synthesis reduces obesity and metabolic dysfunction by promoting brown adipose tissue thermogenesis. Nat Med. 2014;21(2):166-172. doi:10.1038/nm.3766. 